\title{
The obligation of physicians to medical outliers: a Kantian and Hegelian synthesis
} Thomas J Papadimos* and Alan P Marco

\author{
Address: Department of Anesthesiology, Medical College of Ohio, 3000 Arlington Avenue, Toledo, Ohio 43614, USA \\ Email: Thomas J Papadimos* - TPapadimos@mac.com; Alan P Marco - Amarco@mco.edu \\ * Corresponding author
}

Published: 03 June 2004

BMC Medical Ethics 2004, 5:3

This article is available from: http://www.biomedcentral.com/l472-6939/5/3

(c) 2004 Papadimos and Marco; licensee BioMed Central Ltd. This is an Open Access article: verbatim copying and redistribution of this article are permitted in all media for any purpose, provided this notice is preserved along with the article's original URL.
Received: 02 February 2004

Accepted: 03 June 2004

\begin{abstract}
Background: Patients who present to medical practices without health insurance or with serious co-morbidities can become fiscal disasters to those who care for them. Their consumption of scarce resources has caused consternation among providers and institutions, especially as it concerns the amount and type of care they should receive. In fact, some providers may try to avoid caring for them altogether, or at least try to limit their institutional or practice exposure to them.

Discussion: We present a philosophical discourse, with emphasis on the writings of Immanuel Kant and G.F.W. Hegel, as to why physicians have the moral imperative to give such "outliers" considerate and thoughtful care. Outliers are defined and the ideals of morality, responsibility, good will, duty, and principle are applied to the care of patients whose financial means are meager and to those whose care is physiologically futile. Actions of moral worth, unconditional good will, and doing what is right are examined.

Summary: Outliers are a legitimate economic concern to individual practitioners and institutions, however this should not lead to an evasion of care. These patients should be identified early in their course of care, but such identification should be preceded by a well-planned recognition of this burden and appropriate staffing and funding should be secured. A thoughtful team approach by medical practices and their institutions, involving both clinicians and non-clinicians, should be pursued.
\end{abstract}

\section{Background}

Health care providers (and hospitals) in the United States struggle with the costs of health care delivery on a daily basis, frequently facing the daunting prospect of accepting uninsured or under-insured patients with significant comorbidities. Such co-morbidities may result in a prolonged length of stay far exceeding any prospective payment scheme (Diagnosis Related Groups [DRGs] and capitation). DRGs are a classification of hospital case types into groups based on diagnoses, procedures, age, sex and the presence of complications or comorbidities that are expected to have similar hospital resource use. Federal health care programs use this classification to pay for inpatient hospital care. Capitation is the system of payment for each customer served, rather than by service performed. For example, the heart transplant patient who is three years post transplant who now presents with a regurgitant tricuspid valve in his transplanted heart that is in need of repair or replacement may be insured, but he is an extreme challenge physiologically and administratively. He will most likely exceed the average length of stay for 
valve replacement and become an "outlier", the driving force behind hospital costs.

Physicians, and the institutions in which they practice, have tried to control personnel costs, technology costs, and pharmacy costs, but outliers have been beyond their grasp. This small population of patients is a mega-consumer of resources. The futility of their care, the likelihood of poor outcomes, and the overuse of technology and therapeutic modalities in these patients are a subset of issues in the approach to outlier management as opposed to the primary ethical issue of engaging them as patients in medical practices and institutions [1].

Struggles with obligation regarding the care of outliers consume the consciousness of many health care providers, including the authors. Morality, responsibility, good will, duty, acting on principle, justice, and treating people as an end in themselves, as viewed by the authors and supported by the philosophies of Immanuel Kant and G.F.W. Hegel, are explored as a basis for a physician to never disengage from the care of outliers.

From the vantage point of pure reason Kant's Categorical Imperative directs one as to what ought to be done. It is considered "categorical" because it is not dependent on the senses and its value is always overriding. The requirement of duty is expressed by reason. To follow this imperative we must act according to the maxims that are willed to be universal laws. In doing so we determine our action freely and we accept a principle determined by pure reason. Thus, the law we follow is ours and we are autonomous [2]. In other words, as physicians we have a capacity for intentional action and, ideally, we act independent of controlling influences to provide our patients with care based upon the best decisions that we can make while acting "freely" and "purely".

Kant then proceeds to instruct us that we are rational beings (agents whose value is not based on external materiality) and in accepting the categorical imperative we are governed by the laws of reason, not nature. In this way we can will the world to become a place of different rational beings living together, obeying laws, and showing respect for all [2]. In doing so we respect the autonomy of the patient and their family. It is our professional obligation to help them make autonomous choices and to respect their choices. We cannot do this if we disengage from their care.

Kant teaches that there is one morality, but different types of duties. He makes the distinction between strict duties and imperfect (as opposed to perfect) duties. Strict duties involve justice, such as respecting the rights of others and not violating the dignity of others. A perfect duty requires a specific action, such as keeping a promise. An imperfect duty, such as helping others, cannot be demanded as a right by someone else, so there is leeway as to how this right should be respected [2]. All three types of duties encompass a medical practice. A strict duty involving dignity and rights, as mentioned above, is a duty most physician organizations would consider inviolate and demand that their members respect such a duty. However, performance of perfect and imperfect duties is more difficult to secure from an individual. It is the moral physician who can go beyond strict duties and engage the patient in perfect and imperfect duties, as the situation requires.

Kant felt that as man's knowledge grew, man would understand his relative insignificance in the universe, but at the same time such awareness would allow the moral law within him to expand. Thus, as moral beings with infinite value, we would realize the significance and dignity of our position in the cosmos. In having such an infinite value, those of us who become medical "outliers" would deserve attention, consideration, and thoughtful evaluation.

Hegel's Philosophy of Right, which he published during a national political crisis in Prussia in 1821, was drawn upon, in part, to support our maxim. Even though Hegel advanced claims antagonistic to the individual, selfaware/conscious subject in his work, we found certain thoughts he expressed to conform to aspects of our maxim.

As we become self-aware creatures we acquire personality and with personality we can change our physical environment, thus encountering "will". We are thus distinct from nature ("I am I"). Personality essentially involves the capacity for "rights". Hegel goes on to develop the imperative of right, i.e., people have rights that should not be infringed upon. Thus, having a will, and being conscious of that will, allows our self to surface through choice and action $[3,4]$. The "right" to health care does not exist in all societies, but an argument can be made that a patient being cared for by a physician has the "right" to expect the physician will not withdraw from their care.

Hegel allows some instruction in private property and contracts and explains to us how several people looking upon a "thing" as theirs would lead to the clash of one man's right with that of another man [4]. It is not unreasonable that patients would consider their relationship with a physician as a "thing" to which they have a right and that a "clash" could occur if the physician attempted to disengage from the care of the patient.

Hegel then moves on to morality, a requirement of self. He feels morality is an "ought to be or demand". Our 
"selves" are incomplete without the demand of moral law, in other words, the self needs a purpose, and Hegel feels that purpose is to become the embodiment of law. This moral law involves "this identity of my will with the will of others". Here we start to lose our individuality and become conforming social beings. The moral action of a social being is concerned with their own welfare and that of all others. Welfare is identified with the "good" and the "good" is "the absolute end of will" [5]. The question arises as to what physical and financial effort is an individual worth from the societal perspective as it regards their health care. What is "too much effort" by society or by the individual medical practitioner?

Up to this point both Kant and Hegel advance our maxim. However, at this juncture Kant would believe that pure reason could determine right and good, but Hegel would probably differ. According to Hegel a person has a right to only "listen to reason". Here Hegel's social being comes into play at the expense of Kant's "form" of moral will which has applications of universality.

Hegel proceeds to take his social being into the ethical life of valid laws and institutions, such as marriage, family, civil society, and the state. He feels these laws and institutions of society are binding on the individual will. When one is a member of a family there is no dependence, only membership. Personality or individuality is expressed through the family entity. The family and its individuals are then integrated with civil society (the economic level). Civil society is part of the state (political level) and the state "has supreme right against the individual, whose supreme duty is to be a member of the state" [6]. The problem of morality the "self" faced in the abstract is now replaced with duties the individual must fulfill in society to remain virtuous. We have now gone from the abstract to the specific. Society now identifies or defines the universal will and the individual has the duty to perform and conform [6].

Even though a society will try to honor strict duties, such a justice, from the health care vantage point of the medical outlier, perfect duties (keeping a promise) and imperfect duties (helping others) now are subject to a societal and political will. The members of society can influence this will, for or against medical outliers. Regardless of the "prevailing winds" of opinion, physicians must strive to do what is in the best interests of their patients.

Hegel's views of morality and social ethics have important implications. He felt that when considering morality right and wrong was a matter of individual conscience. However, he also indicated to us that man must move beyond individual morality to the level of social ethics. For Hegel duty was not an individual judgment, but only occurred in the context of social relationships. In the end, though, the issues of futility of care and resource allocation cannot be ignored and must be addressed as they concern the welfare of all.

The works of Kant and Hegel uniquely contribute to issues involving medical ethics. Kant's use of reason, pure reason, can be very appealing to those physicians who carry the Hellenistic "ideal" of medicine to their practice. His view on the good will, responsibility, duty, morality, acting on principle, justice, and persons as ends in themselves are very seductive to the idealistic physician.

Even though Hegel demanded sublimation of the individual to the family, civil society and the state, his views on self, personality, capacity for rights, right and wrong, morality, welfare and the conscience lend themselves to our maxim. His positions on the family, civil society, and the State may be leveraged against this sublimation of the individual if (1) doing what is best for a minority of individuals (medical outliers) morally strengthens the family, society and the State, and if (2) that burden of medical outliers (financial and otherwise) is borne by the entirety of a moral society. The views of Hegel may thus be compatible with Kant in supporting our maxim.

\section{Discussion \\ What is an outlier?}

During our graduate work an outlier was a point on a graph that was more than two standard deviations away from the midpoint of a normal distribution. According to Dorland's Illustrated Medical Dictionary an outlier is "an observation so distant from the central mass of data that it is considered an obvious mistake that should be removed from the data whether or not a cause of the deviation can be found" [7]. Later, as practitioners of the healing arts, we discovered that we could be outliers if we consumed too many of a hospital's resources. Thus, our conceptualization of an outlier progresses from the abstract to the personal.

Hospitals may even become outliers if their adjusted mortality rates exceed the norms. Adjusted mortality rates, of course, may not be a reliable screening tool to determine the outlier status of a hospital [8]. Hospitals are not persons and there is little emotional context when looking at them as outliers.

However, the dilemma of patients as outliers presents a moral conundrum. They are neither points on a graph, nor can they be chastised economically for their illness or socioeconomic status. A patient can be an outlier if admitted to a low-volume, high variation, DRG. This inherent variability in such patients causes a financial risk to the institution to which they are admitted, and, in turn, hos- 
pitals' excessive claims for outlier payments may put the state at risk, i.e., the upsetting of Medicare regulation in America $[9,10]$.

Such patients are also outliers if their lengths of stay exceed the mean by 20 days or 1.94 standard deviations, whichever is less [11]. Even if the length of stay is within accepted bounds, the patient can be deemed an outlier because of increased resource utilization [12].

This definition can further be refined using basic, automated, routinely gathered laboratory data to help "the discriminatory power of risk models based on administrative data with abstracted diagnoses" [13]. Adding laboratory data to the analysis can improve an administration's ability to identify providers with possible exceptional quality of care. This model allows identification of "outlier" wards.

Patients as outliers seem to present in two ways. They are either identified before admission or after. In the first case, they are recognized as potential outliers before admission because of their co-morbidities or financial status/health insurance and are identified as likely to be a financial burden upon the institution. The moral imperative of their situation drives most physicians to care for them, but those same physicians and the hospital administrators with whom they work realize the potential fiscal dilemma that these patients present.

In the second case, the patient is already hospitalized and his illness has caused an unexpected, protracted length of stay with no end in sight. A transplant patient receiving immunosuppressive therapy presenting for a major surgery may be such an example. The immunosuppressive drugs are necessary for the continued viability of the transplant, but these medications do not allow the patient's new wound to heal. Infections may occur; the patient may become septic, but does not die. He marginally exists on the ventilator with a tracheotomy, receives renal dialysis for his now failing kidneys, antibiotics for sepsis, invasive monitors, expensive nutritional formulas, and multiple debridements of his wound or other surgical procedures. His care is now greater than 90 intensive care days and life support is not withdrawn because he is cognitively intact. These two types of outliers generally result in one of the following clinical outcomes: 1) they die after prolonged hospital stays; 2) they survive hospitalizations, only to die soon after being discharged or if they survive, never recover their pre-hospital function; or 3) they survive the hospitalization and return to their pre-hospitalization functional status [14].

An outlier, in this context, is a human being who suffers an incredible physiologic, emotional, and financial bur- den; who, in turn, will cause health care providers and administrators economic and psychological stress. An outlier can be recognized, an outlier will cost money, and an outlier will tax emotions. Why stay engaged in their care?

\section{Morality}

All physicians like to think of themselves as "moral" individuals. Morality is something required and demanded by the "self" [15]. It is something that universally "ought to be". There is a universal conception of how a physician should respond to a patient (one who suffers). "Hurt no one; rather help all as much as you can" is the basic moral premise with which many moral philosophers agree [16].

Moral law requires moral demands and our inability to meet all such moral demands indicates that our "self " is incomplete. To compensate for our incompleteness as moral physicians we seek purpose or aim. This notion of aim allows us to try to become what we "ought" to be, to aspire "to become the actual, objective embodiment of what ought to be" [15].

This moral law and the physician's response to it should be a "universal" response; its moral essence should be applicable to all practitioners. The physician should meld reason and moral essence with social welfare and enter the moral corridor where a physician's aim is to identify his or her will with the will of the patient. The physician tries to positively influence the will of others (family and civil society) to the benefit of the patient and represents the will of the patient to other health care providers, the patient's family, and to civil society/the state.

According to Hegel, moral action has a special context. That context is welfare, not only an individual's welfare, but also the welfare of all. Moral action improving the welfare of the individual and the whole is a "good"; therefore, "welfare" and "good" become synonymous. To know the "good" means subjugation of individual will, and to understand that morality demands realization of the good, the universal welfare of all [15]. The universal welfare requires the care of outliers by the moral physician.

\section{Responsibility}

Physicians are morally responsible for the care of outliers, as individual practitioners and as a collective. This responsibility can only be evaded if four conditions are met, which would be morally, ethically, and intellectually incompatible with being a moral physician.

First, the evasive physician would claim only to be responsible for only the effects of those aspects of care of which he or she was conscious. For example, the physician 
ordered a blood transfusion and it happened to be contaminated with bacteria that resulted in the patient's death. He was not responsible because he had no way of knowing that the blood was contaminated. Physicians may subconsciously delude themselves that their patient will not be an outlier or will find medical insurance (through "the government") and thus deny responsibility for admitting an outlier to the hospital [15].

Second, the evasive physician could claim that he is not responsible because all actions can lead to varied outcomes, not all of which can be foreseen, and that other causal factors intruded to give the patient a bad outcome. This can only be claimed when best practices are followed. Not providing the best or appropriate care for a patient with severe co-morbidities or lack of health insurance leads to only one consequence; poor outcomes and the suffering of patients and their families [15].

Third, the evasive physician claims responsibility only for those aspects of their actions that they willed or intended to produce. This claim is simply foolish. Physicians intend many good things, but are actually responsible for varied consequences, even if the consequences are unintended. An errant ball may break a window at a sandlot soccer game. The player did not intend this, but is still responsible [15].

Fourth, the evasive physician must deny that "the value of an action lies in its objective end, what it accomplishes in the external world of fact (good care of the patient); its value does not lie in the subjective satisfactions a physician derives from achieving his or her ends" [15]. There is no getting around this statement. If a physician does not provide care for an outlier this inaction will speak to the external world clearly. He may be satisfied that he has avoided work or risk, but such inaction does not have external value.

None of the above mentioned four conditions can be voided by the moral physician. Therefore, the moral physician has responsibility. Such an argument can be extended to other health professionals and administrators.

\section{Good Will}

A moral physician must exhibit good will, an unconditional "good". A good will is the only thing good without qualification,

"It is impossible to conceive anything at all in the world, or even out of it, which can be taken as good without qualification, except a "good will" [17].

Such a "good" cannot be tarnished because it has unconditional worth. In the outlier such a good will may not be effective enough to cure the person, it may amount to little success, but "even then it would shine like a jewel for its own sake as something which has its full value in itself" [17]. Human beings are, for the most part, rational and have the power to reason. This power to reason influences the will because,

"its true function must be to produce a will which is good, not as a means to some further end, but in itself" [17].

If moral principle (see below) motivates a physician's will it is always and necessarily good. Physicians must control their moral status; it is the distinctive expression of their humanity. By controlling our will, "goodness" will only depend on us. Therefore, our attitude greatly influences our moral character. We have the ability to reason so that we can produce the best of "goods" as physicians, the good will, and in so doing, unconditionally provide it to an outlier.

\section{Duty}

Performing our duty can sometimes be difficult. Reason demands that we do what is right, but our desire can interfere with what we ought to do. We may not really desire to take care of those who cannot pay and we do not really desire to take care of a ventilator-dependent patient for weeks on end, but Kant places duty at the center of a moral life. We must free ourselves from the desire not to engage such patients if we are to lead a moral life. This kind of conflict between reason and desire obviously does not occur at all times in the care of outliers. Many times we find that our desires to overcome challenges and our duty are congruent and it is easy to do our duty. However, Kant cautions us,

"that we should not be fooled by an occasional coincidence of inclination and duty into thinking that warm feelings for others bestow moral worth on our actions. Nor is it enough to act in accordance with duty, from whatever motive, in order for our behavior to have moral worth. Helping our neighbor is required by duty, but helping our neighbor has no moral worth if done out of an inclination to help others. Moral worth is achieved only if we act from duty, that is to say, only if we act out of an appreciation of the fact that the act is our duty" [17].

In order for a physician's good will to have moral worth it must spring forth from duty. We frequently feel sorry for our patients. Yet this motivation does not spring from duty. There are two reasons as to why sympathy cannot bestow moral worth on a deed. First, the physician may have sympathy for someone who does not deserve it, but in turn not exhibit sympathy for someone who does deserve it. Sympathy is an inclination and all inclinations are unreliable as vectors for moral actions. In the second 
case, sympathy lacks moral content. If you treat a patient out of sympathy your are satisfying an internal need rather than an external good, and not doing something that is of moral value. Therefore, only the motive of duty bestows moral worth on an action [5].

Evidence of moral worth in doing our duty is most clear when physicians and other health care professionals are not inclined to do their duty because it costs them time or money, but do so nevertheless. Taking care of outliers is something many providers and institutions do not like, or even have to do, but in doing so provide society with an example of "beneficent action having moral worth " [5].

\section{Principle}

What is the motive of a morally worthy action? Moral worth depends "on the principle of volition in accordance with which, irrespective of all objects of the faculty of desire, the action has been performed" [17]. The purpose and goals of our actions are not what is important. Moral worth is bestowed on physicians and their interactions with patients because principle is motivating them. This is a further elucidation of the "good will." The moral physician will act out of a sense of duty when he or she acts on principle. Principle makes us do what we ought to do (duty).

As physicians and health care professionals we must lead the moral life, i.e., the life of principle. The moral person is the one who is principled. A principled person does the right thing out of reason and the general consideration of how a human being should act. Principle places moral worth on the action and thereby on the physician or health care professional.

\section{Justice}

Medical outliers are due justice. Kant states that, "Any action is just if it can coexist with everyone's freedom in accordance with a universal law" [18]. In other words, an action is just if it respects the freedom of others, and does so not accidentally, but on principle. Every action must respect the freedom of every individual [19].

Kant feels that freedom is a natural right, "Freedom, in so far as it is can coexist with the freedom of every other in accordance with a universal law, is the only original right belonging to every man by virtue of his humanity" [18]. Kant is now taking the path toward human rights. The right to which he refers is universal and cannot be suborned by legislation or budget limitations.

Of course physicians are also due justice. It is difficult to force an individual to care for another against their will. However, if a patient or their family wishes to engage in an attempt at preserving their life or that of a loved one, the opportunity to make such an effort cannot be curtailed in a moral or ethical society. It can be argued that monetary funds are limited, but is help from a physician limited? Where do virtue and morality come into focus? Must virtue and morality be subject only to remuneration? Is there not some special covenant in accepting the mantle of being a physician? These questions can be debated, but not legislated, and the answers (views) will vary from physician to physician.

If no one attends to medical outliers they, or their families, may consider themselves as being wronged, i.e., not receiving justice. Hegel's views on coercion and crime may be appropriate to the discussion at this time. It is true that the concept of medical outliers, transplantation medicine, and extended length of stay were unknown to Hegel, but some of his thoughts may be applicable.

Hegel claims, "the free will cannot be coerced at all" [4], but goes on to say, "only the will which allows itself to be coerced can in any way be coerced" [4]. If you or loved one lay dying how can one not feel coercion if another party (the physician or a hospital) is trying to withdraw or not attend to the patient? Force or coercion is in its very conception directly self-destructive [4]. Furthermore,

"Wrong in the full sense of the word is crime, where there is no respect either for the principle or rightness or for what seems right to me, where, then, both sides, the objective and subjective, are infringed" [20].

If a patient is in an emergency department, hospital room, or in a physician's office the practitioner will be hardpressed to be considered just if (a) he or she does not care for the patient or (b) does not find another physician to care for the patient (and in such situations in America the physician may actually be committing a tort, i.e., a civil rather than criminal wrong for which the law provides a remedy) [21].

Hegel makes reference to contracts in regard to possession of property, but an extension of this thinking, as is provided in the preceding paragraph, can be recognized in American courts today as a contract. When a physician or a practitioner in his or her employ encounters any patient this may result in a contract, or covenant, i.e., a common will [19].

Accordingly, "The covenant, made manifest in a symbol [the patient encounter-our interpretation], and its performance (the particular will) are quite distinct" [20], but, "in a contract, to be sure, making a covenant entails the right to require its performance" [20]. Ergo, there is a requirement of justice for the medical outlier. 


\section{Outliers exist as an end-in-themselves}

Our patients who are outliers must never be treated just as things, black holes, or expensive DRGs. They are people who have an absolute worth in themselves. Kant would agree:

"Now I say that man, and in general every rational being, exists as an end in himself, not merely as a means for arbitrary use by this or that will: he must in all his actions, whether they are directed to himself or to other rational beings, always be viewed at the same time as an end" [italics added by authors] [17].

R.L. Arrington helps us interpret Kant further by stating that,

"Each of us is a person, not just a thing to be used, a means to someone else's pleasure or well-being, and our personhood consists in our status as a rational agent of worth. All persons qua rational agents have unconditioned value in themselves as ends - such is the pronouncement of reason and morality" [5].

The old maxim of "do unto others as you would have them do unto you" is very appropriate here. Whatever we think is right for us, as providers, is also right for all other rational creatures, including outliers. Whatever we ask others to do, we must be willing to do ourselves. It is universal that we:

"Act only on that maxim through which you can at the same time will that it should become a universal law" [17].

Kant, and the authors, feel that as principled providers of health care, the duty to help (outliers) is imposed on us not only in acknowledging that our patients are worthy ends in themselves, but that we should also advance their ends. Honoring these duties brings merit upon us.

\section{The state, futility of care, and the welfare of all}

As physicians we express concern about the individual patient and we tend to be patient advocates. Kant's ideas about morality, duty, obligation, principle, etc. easily meld into the daily practice of western medicine as it applies to the individual.

Hegel, though, has historically been conceptually more difficult in regard to supporting the individual as it concerns the welfare of all, futility of care, and the government's place in such topics.

"The state has the supreme right against the individual, whose supreme duty is to be a member of the state" [6]. This is quite a formidable statement on Hegel's part. Espe- cially when thoughts such as, "The rational end of man is life in the state" [20], and "Permission to enter or leave it must be given by the state" [20], and finally, "Hence if the state claims life, the individual must surrender it" [20] are offered in support of individual sublimation to the state.

These statements are made in a political context, but nonetheless are implied threats to the individual who uses scarce resources. So one may flippantly ask why are not medical outliers justified in ending their existence themselves? Hegel's initial response to such an interrogative is, "But as for an unqualified right to suicide, we must simply say that there is no such thing, even for heroes" [20]. Hegel explains himself further as he addresses notions of "property" in relation to living:

"There is therefore no unqualified right to sacrifice one's life. To such a sacrifice nothing is entitled except an ethical Idea as that in which this immediately single personality has vanished and to whose power it is actually subjected. Just as life as such is immediate, so death is its immediate negation and hence must come from without, either by natural causes, or else, in the service of the Idea, by the hand of a foreigner" [20].

Of course Hegel was never confronted with the topics of palliative care and euthanasia (ending of life at the request of the medical outlier, not the state). His feelings on suicide probably refer to the able-bodied citizens of the state who are of use to the state. From the patient's perspective he seems to allow an argument of self-determination when he states, "I possess the members of my body, my life, only so long as I will to possess them" [20]. Nonetheless, some sort of process should be available to address care alternatives for the individual.

Should the state care what its citizens think about medical outliers? Should how the public feels about medical outliers influence a government's position? Hegel says,

"Public opinion, therefore, is a repository not only of the genuine needs and correct tendencies of common life, but also, in form of common sense (i.e., all-pervasive fundamental ethical principles disguised as prejudices), of the eternal, substantive principles of justice, the time content and result of legislation, the whole constitution, and the general position of the state" [20].

Public opinion is the collective will of individuals and may result in formulation of a general position of the state (at least in a free society) in regard to medical outliers. A citizen's will counts in such a society. The will of many individuals becomes a collective will. If that collective will is the majority in a free society, and if that collective will can persevere and endure, it will become the position of 
the government. The government's will, therefore, is the will of the people.

As an example, the number of aged Americans will be an increasingly significant portion of the population. They can potentially be an enormous collective will. This aging population will have assets and voting power. Inculcated into this population is a conscious history of the authors' maxim (which has been the traditional position in the United States). If the people who form the collective will can imagine themselves as medical outliers, and many of them do so (catastrophic medical insurance is being bought by an increasing number of individuals), this collective will may be found to be congruent with that of the individual.

This population will expect engagement of their physician in their care, regardless of the expiration of hospital care eligibility or government resources. In the event of economic scarcity this population will not only hope for support from their family, but they will expect their physician to be their advocate and guide them and their family through waters that are difficult to navigate. The physician may very well become the "negotiator" of health care. The physician's continued engagement with patients will be paramount.

An emphasis placed on "never disengaging" from the care of outliers is consequently followed by a myriad of questions regarding futile care. Resource allocation is a problem confronting the "engaged" outlier and his health care providers. While posing the question of how to make a fair decision in allocation of scarce resources is inevitable, it is beyond the scope of this paper. It is sufficient to say that such decisions in regard to allocation of resources occur simultaneously at the governmental, hospital, and bedside levels along with evidence-based medicine and benefit analysis. Dr. Peter A. Singer, of the University of Toronto, explains that "decisions over resource allocation can be mitigated through three general strategies: 1) don't do things that don't work; 2) don't do things that do work, but the patients don't want done; and 3) don't do things inefficiently" [22].

Health care providers are left with five questions that need to be answered in regard to allocation of scarce medical resources:

1. How much should we favor producing the best outcome with our limited resources?

2. When should we allow the aggregation of modest benefits to more people to outweigh more substantial benefits to fewer people?
3. How much priority should we give to treating the sickest or most disabled patients?

4. When must we rely on fair democratic process as the only way to determine what constitutes a fair rationing policy?

5. When resources are limited, should we fund a program where there is high-quality evidence of a small benefit or one where there is lower-quality evidence of a large benefit [22]?

While it is the physician's duty to care for an outlier, the constraints of societal and organizational allocation of resources may affect the physician's level of intervention and "engagement." Futile care need not be provided because it does not benefit the patient. We have to be careful that our internal desire to control/allocate resources does not intrude on our determination of benefit; at the same time we must realize that serious consideration of futile end-of-life care does not generally receive enough attention $[23,24]$.

\section{Conclusion}

Patients who become outliers in the physiologic or economic sense present legitimate concerns to health care providers, insurers, institutions, and health care systems. These concerns should not be translated into a plan for evasion of their care, but should result in a well-planned approach to staffing, securing of funding, and locating alternative funding sources for these patients. Identifying outliers early in the admissions process may lead to later facilitation of their care. When unanticipated complications arise during the care of patient it would be prudent to develop a team approach to that individual early in the course of care using the experience of other physicians, nurses, allied health care professionals and administrators to help resolve the difficulties that will most definitely ensue. This team approach, or provision of an infrastructure dealing with outlier management, is important so that ethical conflicts rarely occur. The approach should focus on patients and their loved ones to provide guidance and understanding regarding the clinical course and potential outcome of the illness, thus avoiding potential ethical dilemmas between the physician's duty to outliers and the duty to society via the allocation of health care resources. Duty and principle command us to provide care to outliers. The health care community bears moral responsibility for the care of all citizens.

An idealistic argument has just been made, on behalf of our patients, which carries the moral strength of a hurricane, but the economic strength of a summer breeze. Rational and adequate planning and funding are necessary for the task at hand, however the question of futile 
care and use of scarce resources is daunting. Cooperation among private and public sectors, profit and not-for-profit organizations, labor, religion, and academic entities is paramount.

In the end our actions as moral agents are what count. We must always remain principled, demonstrate "good will", act responsibly out of duty, and treat patients as an endin-themselves.

\section{Summary}

Patients who are outliers are a legitimate economic concern of health practitioners and medical institutions. Evasion of the care of outliers is not morally acceptable. Physicians, because of their training and position in society to heal, must remain moral agents who stand and deliver that which is needed by outliers. Such a view is idealistic and structuring it into medical practices and hospital settings with existing reimbursement systems and scarce resources, especially with an aging population and new technologies, must be acknowledged as difficult.

The debate presented here, in which physicians are characterized as moral agents, is not naïve. The problem is real. The views of Kant and Hegel, although seemingly incompatible, are precisely the two "opposite" poles that must be reconciled, i.e., a synthesis of the moral obligation of individuals, institutions, and society to each other while considering the welfare of all.

Such a tasking recognizes that: (1) the inevitable entrance of such patients into medical practices and institutions is burdensome economically and psychologically, (2) a "team" approach involving clinicians and administrators is needed to identify medical outliers upon their initial presentation so as to coordinate their support, and (3) simply making budget adjustments and seeking more support (monetary and otherwise) may not be enough. A collective electoral "will" may be necessary to determine how much of a state's wealth should be available to medial outliers.

\section{Competing interests}

None declared.

\section{Authors' contributions}

TJP and APM were both involved in the background, summary and the discussion portion of "what is an outlier? ". TJP and APM wrote the discussion portion regarding the state, futility of care, and the welfare of all. TJP wrote the remaining portions of the paper with editing assistance from APM. Both authors understand and agree with the entire paper.

\section{References}

I. Becker C: If you have it, you use it. Latest Blues association study finds new technology not only drives demand but also increases spending. Mod Healthcare 2003, 45:9-II.

2. Ameriks K: Immanuel Kant. In The Cambridge Dictionary of Philosophy 2nd edition. Edited by: Audi R. Cambridge: Cambridge University Press; 200I:460-466.

3. Westphal M: Kierkagaard and Hegel. In The Cambridge Companion to Kierkagaard Edited by: Hannay A, Marino GD. Cambridge: Cambridge University Press; 1998: I01-124.

4. Hegel GFW: Abstract Right. In The Philosophy of Right Edited by: Knox TM. London: Oxford University Press; 1967:37-74.

5. Arrington RL: Western Ethics: an Historical Perspective Madden MA: Blackwell; 1998.

6. Hegel GFW: Ethical Life. In Philosophy of Right Edited by: Knox TM. London: Oxford University Press; 1967: 105-223.

7. Anderson DM, Keith J, Novak PD, Elliot MA: Dorland's Illustrated Medical Dictionary Philadelphia: Saunders; 1998.

8. Zalkind DL, Eastaugh SR: Mortality rates as an indicator of hospital quality. Hosp Health Serv Admin 1997, 42:3-I5.

9. Takeri PA, Butz DA, Dechert R, Greenfield LJ: How DRGs hurt academic health care centers. Am Coll Surg 2001, 193:I-8.

10. Brock TH: CMS investigates outlier payments. Healthc Financ Manage 2003, 57:70-74.

II. Burnett DM, Cifu DX, Kolakowsky-Hayden S, Kreutzer JS: Predicting change outliers after spinal cord injury: a multi-center analysis of demographics, injury characteristics, outcomes, and rehabilitation changes. Arch Phys Med Rehab 2001, 82: I|4-II9.

12. Medical Dictionary Online [http://www.online-medical-diction ary.org/?q=outlier\%2+DRG]

13. Maor Y, Rubin HR, Gabbai U, Mozes B: The importance of laboratory data comparing outcomes and detecting outlier wards in the treatment of patients with pneumonia. $J$ Health Serv Res Policy 1998, 3:39-43.

14. Ahrens $\mathrm{T}$ : Outlier management: influencing the highest resource-consuming areas in acute and critical care. Crit Care Nurs Clin North Am 1999, I I:107-1 I6.

15. Hegel GWF: Morality. In Philosophy of Right Edited by: Knox TM. London: Oxford University Press; 1967:75-104.

16. Nietzsche F: Beyond Good and Evil. In Basic Writings of Nietzsche 2nd edition. Edited by: Kaufman W. New York: Modern Library; 1968: 186.

17. Kant I: Critique of Practical Reason Edited by: Beck LW. New York: Macmillan; 1993.

18. Kant I: Metaphysical first principles of the doctrine of right. In Metaphysics of Morals Edited by: Gregor M. Cambridge: Cambridge University Press; 1996.

19. Scruton R: Enlightenment and Law. In Kant A Very Short Introduction Oxford: Oxford University Press; 2001:I I2-128.

20. Hegel GFW: Additions. In Philosophy of Right Edited by: Knox TM. London: Oxford University Press; 1967:224-297.

21. American Medical Association Code of Ethics [http:// imc.gsm.com/demos/dddemo/consult/abandon.html]

22. Singer PA: Resource allocation: beyond evidence-based medicine and cost-effectiveness analysis. ACP J Club 1997, 127:Al6-A18.

23. Hariharan S, Mosely HSL, Kumar AY, Walrond ER, Jonnalagadda R: Futility-of-care decisions in the treatment of moribund intensive care patients in a developing country. Can J Anaesth 2003, 50:847-852.

24. Romesberg TL: Futile care and the neonate. Adv Neonatal Care 2003, 3:213-219.

\section{Pre-publication history}

The pre-publication history for this paper can be accessed here:

http://www.biomedcentral.com/1472-6939/5/3/prepub 